\title{
Design and Implementation of a Fuzzy Controller for Small Rotation Angles
}

\author{
Mohammed Mahmood Hussein \\ Computer Engineering Department \\ College of Engineering \\ University of Mosul \\ Mosul - IRAQ \\ mohmah86@gmail.com
}

\begin{abstract}
This paper present an adaptation mechanism for fuzzy logic controller FLC in order to perfect the response performance against small rotation angles of real D.C. motor with unknown parameters. A supervisor fuzzy controller SFC is designed to continuously adjust, on-line, the universe of discourse UOD of the basic fuzzy controller BFC input variables based on position error and change of position error. Performance of the proposed adaptive fuzzy controller is compared with corresponding conventional FLC in terms of several performance measures such rise time, settling time, peak overshoot, and steady state error. The system design and implementation are carried out using LabVIEW 2009 with NI PCI-6251 data acquisition DAQ card. The practical results demonstrate using self tuning FLC scheme grant a better performance as compared with conventional FLC which is incapable of rotating a motor if the rotation angle is being small.
\end{abstract}

Keywords - Fuzzy Logic Controller, Self Tuning Controller, Universe of Discourse, Position Control, LabVIEW.

\section{INTRODUCTION}

The DC motors have been popular in the industry control area for a long time, it have speed-control capability, which means that speed, torque, and even direction of rotation can be changed at any time to meet new conditions. To control DC motor two factors are considered, the moment of inertia and the static friction. The moment of inertia is the tendency of a motor to remain at rest or in motion unless acted on by an external force; the larger the moment of inertia, the more torque it takes to get it moving or spin the motor about the designated axis. And the static friction is the friction force that must be overcome to get an object at rest to start moving. This very nonlinear effect makes precise control of angular position difficult that is the main contribution of this paper [1][2].

Fuzzy Logic introduced by L.A. Zadeh [3], is currently being used in a wide variety of engineering applications particularly in the area of control such as speed and position control of DC motor. To cope with changing operation conditions of the plant and to adjust for an ill-defined fuzzy control parameters, membership functions (MFs) or scaling factors or the rule base are adapted by self-tuning or selforganizing algorithms according to previous responses until a desired control performance is achieved. Self-tuning FLCs modify the fuzzy membership functions [4] or the scaling factors[5], self-organizing FLCs adjust or learn the rules during the process of control[6].

Coarse and fine tuning method of the fuzzy controller is presented in [7], in which one of two fuzzy controller implemented as look up table is selected to control the plant based on the magnitude of error. Under normal operating conditions or small change in setpoint the controller uses fine control whereas under situation of disturbance or large change in setpoint, it uses coarse control [8]. There are different methods which are used to implement this type of tuning, using two or more sets of fuzzy rules [7], or changing the UOD for each input variable by self-regulating scaling factors [9], or by modification the UOD of the input variables using a nonlinear function [10].

in this paper a novel design methodology is presented by constructing the self tuning FLC from two main parts: a BFC which produces the output control signal, and a SFC to adjust the UOD of the basic controller input variables. The whole system has been designed and implemented for position control of a real DC motor using LabVIEW program with LabVIEW Control Design and Simulation Module and LabVIEW PID and Fuzzy Logic Toolkit.

\section{THE PROPOSED CONTROLLER}

Fuzzy logic controller is called adaptive if any one of its tunable parameters (scaling factors, membership functions,...etc) changes when the controller is being used [11]. In this paper, a supervisor fuzzy controller (SFC) is added to automatically varying, on line, the range of universe of discourse of the BFC input variables. The block diagram of the proposed self tuning fuzzy logic controller is shown in figure 1 . 
The BFC is a two-dimension FLC with two inputs, position error $(\mathrm{E}(\mathrm{k}))$ and change of position error $(\Delta \mathrm{E}(\mathrm{k}))$ and single output $(\mathrm{u}(\mathrm{k}))$ representing the control signal to the motor. The seven triangular membership functions are adopted to define the linguistic values (NB, NM, NS, ZE, PS, PM, PB) in the normalized UOD $[-1,+1]$ for the inputs $(\mathrm{E}, \Delta \mathrm{E})$ and output $(\mathrm{u})$ variables as shown in figure 2.

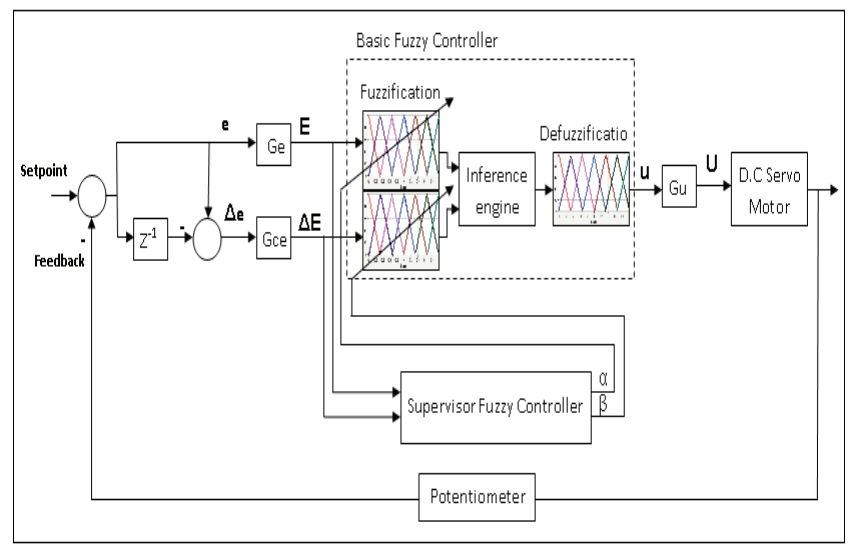

Figure 1. Structure of the proposed self tuning fuzzy logic controller

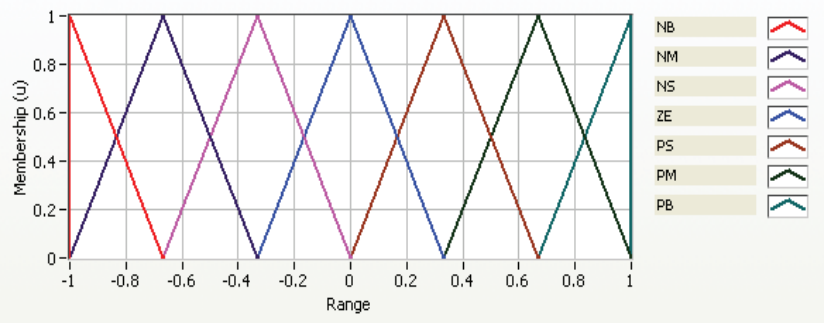

Figure 2. Membership function for $\mathrm{E}, \Delta \mathrm{E}$, and $\mathrm{u}$

The controller action is based on mamdany fuzzy type, center of gravity defuzzification method, Min-Max inference engine. Fuzzy rule base is the core of the fuzzy controller design, which states the relationship between the input domain fuzzy sets and output domain fuzzy sets. These rules are derived from a step response curve of closed loop system and represented in tabular form as shown in table I. Figure 3 depicts a control surface of the BFC.

TABLE I. RULE BASE FOR BASIC FUZZY CONTROLLER

\begin{tabular}{||c||c|c|c|c|c|c|c||}
\hline \multicolumn{1}{|l|}{$\mathbf{E}$} & NB & NM & NS & ZE & PS & PM & PB \\
\hline \hline NB & NB & NB & NB & NM & NS & NS & ZE \\
\hline NM & NB & NM & NM & NM & NS & ZE & PS \\
\hline NS & NB & NM & NS & NS & ZE & PS & PM \\
\hline ZE & NB & NM & NS & ZE & PS & PM & PB \\
\hline PS & NM & NS & ZE & PS & PS & PM & PB \\
\hline PM & NS & ZE & PS & PM & PM & PM & PB \\
\hline PB & ZE & PS & PS & PM & PB & PB & PB \\
\hline
\end{tabular}

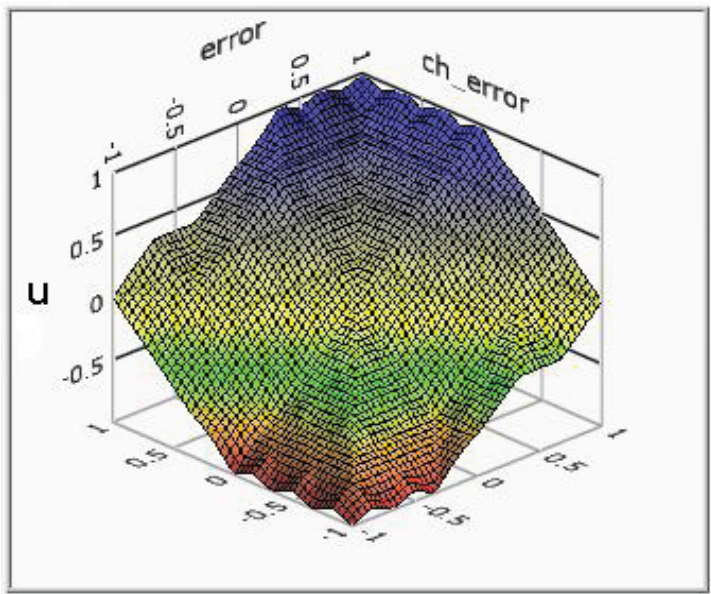

Figure 3. Control surface for the basic fuzzy controller

A SFC has also two input variables $(\mathrm{E}(\mathrm{k}), \Delta \mathrm{E}(\mathrm{k}))$ and two output variables $(\alpha(\mathrm{k}), \beta(\mathrm{k}))$, where $\alpha$ represents the current UOD of the BFC input variable $\mathrm{E}$, and $\beta$ represents the current $\mathrm{UOD}$ of the $\mathrm{BFC}$ input variable $\triangle \mathrm{E}$. Each of the input variables of the SFC are represented by seven triangular membership functions and defined on the common normalized UOD $[-1,+1]$ as shown in figure 2 , whereas the output variables are represented by five triangular membership functions and defined on the normalized domain $[0,+1]$ as shown in figure 4.

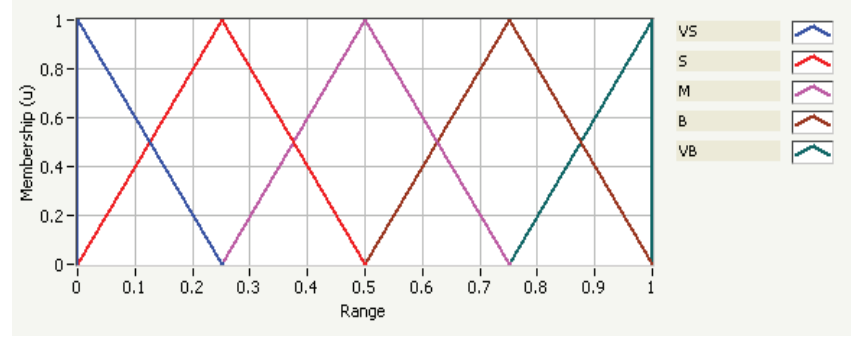

Figure 4. Membership function for $\alpha$ and $\beta$

SFC is used to adjust the UOD of the BFC's input variables. When $\mathrm{E}$ and $\Delta \mathrm{E}$ values are small, a high controller resolution is required therefore the values of $\alpha$ and $\beta$ must be smaller to decrease the range of UOD. On the other hand, when $\mathrm{E}$ and $\Delta \mathrm{E}$ values are big a low controller resolution is required therefore the values of $\alpha$ and $\beta$ must be bigger to increase the range of UOD. Based on the above analysis, the SFC rule base can be summarized in tabular form as shown in tables II and III. Figures 5 and 6 depict a control surface of the SFC for $\alpha$ and $\beta$ respectively. 
TABLE II. RULE BASE FOR $\alpha$

\begin{tabular}{||c|c|c|c|c|c|c|c||}
\hline \multicolumn{1}{|r|}{$\mathbf{E}$} & NB & NM & NS & ZE & PS & PM & PB \\
\hline \hline NB & VB & VB & S & VS & S & B & VB \\
\hline NM & VB & VB & S & VS & S & M & VB \\
\hline NS & VB & VB & VS & VS & VS & M & VB \\
\hline ZE & VB & M & VS & VS & VS & VB & VB \\
\hline PS & VB & M & VS & VS & VS & VB & VB \\
\hline PM & B & B & S & VS & S & VB & B \\
\hline PB & B & B & S & VS & B & B & B \\
\hline
\end{tabular}

TABLE III. RULE BASE FOR $\beta$

\begin{tabular}{||c|c|c|c|c|c|c|c||}
\hline \multicolumn{1}{|r|}{$\mathbf{E}$} & NB & NM & NS & ZE & PS & PM & PB \\
\hline \hline NB & VB & VB & VB & VS & VS & VS & S \\
\hline NM & VB & VB & VB & VS & VS & S & S \\
\hline NS & VB & B & B & M & S & S & VS \\
\hline ZE & VS & S & VS & VS & VS & S & VS \\
\hline PS & VS & S & S & M & B & B & VB \\
\hline PM & S & S & VS & VS & VB & VB & VB \\
\hline PB & S & VS & VS & VS & VB & VB & VB \\
\hline \hline
\end{tabular}

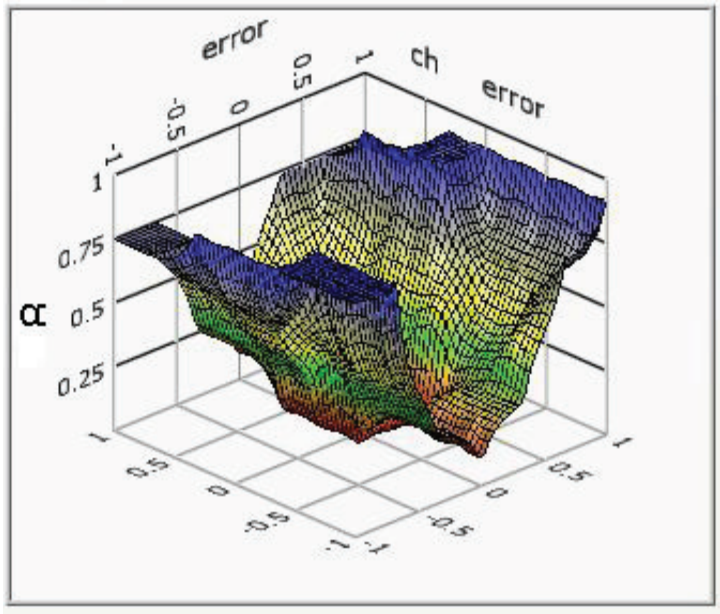

Figure 5. Control surface for $\alpha$

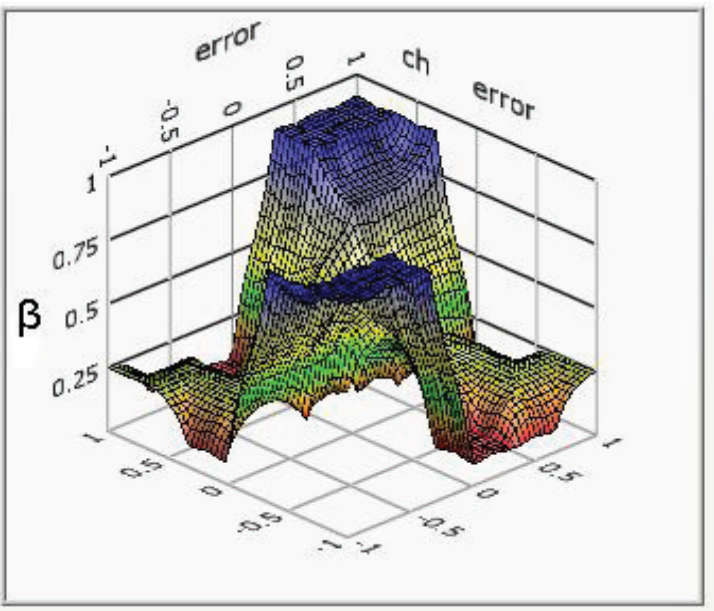

Figure 6. Control surface for $\beta$

\section{APPLICATION AND RESULTS}

The whole system structure is shown in figure 7 . Where, the output of the proposed controller is the control signal to the motor that is send via NI PCI-6251 National semiconductor DAQ analog output and the current position is read continuously in real time through DAQ card analog input.

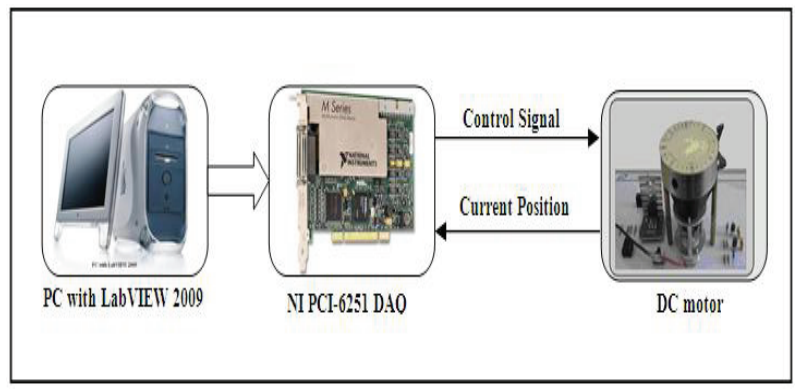

Figure 7. Whole system structure

The proposed self tuning fuzzy logic controller is designed and implemented using LabVIEW 2009 software program. LabVIEW program has two main parts, a front panel that is used for user interactions and display the system real time response and the measuring performance parameters such as rise time, settling time, peak overshoot, and steady state error. The second part is a block diagram representing the source code and is constructed using graphical programming language. Figure 8 shows the LabVIEW block diagram of the proposed controller that is used practically in real time for position control via DC servo motor. This motor requires $(0.32 \mathrm{~V})$ to rotate if it is in standstill state (Stopped) when used in open-loop control system. On the other hand, when it is used in a close-loop system with conventional fuzzy controller (without supervisor fuzzy controller) it doesn't rotate if the difference between the set point (Desired Position) and the current position is less than $3^{\circ}$. 


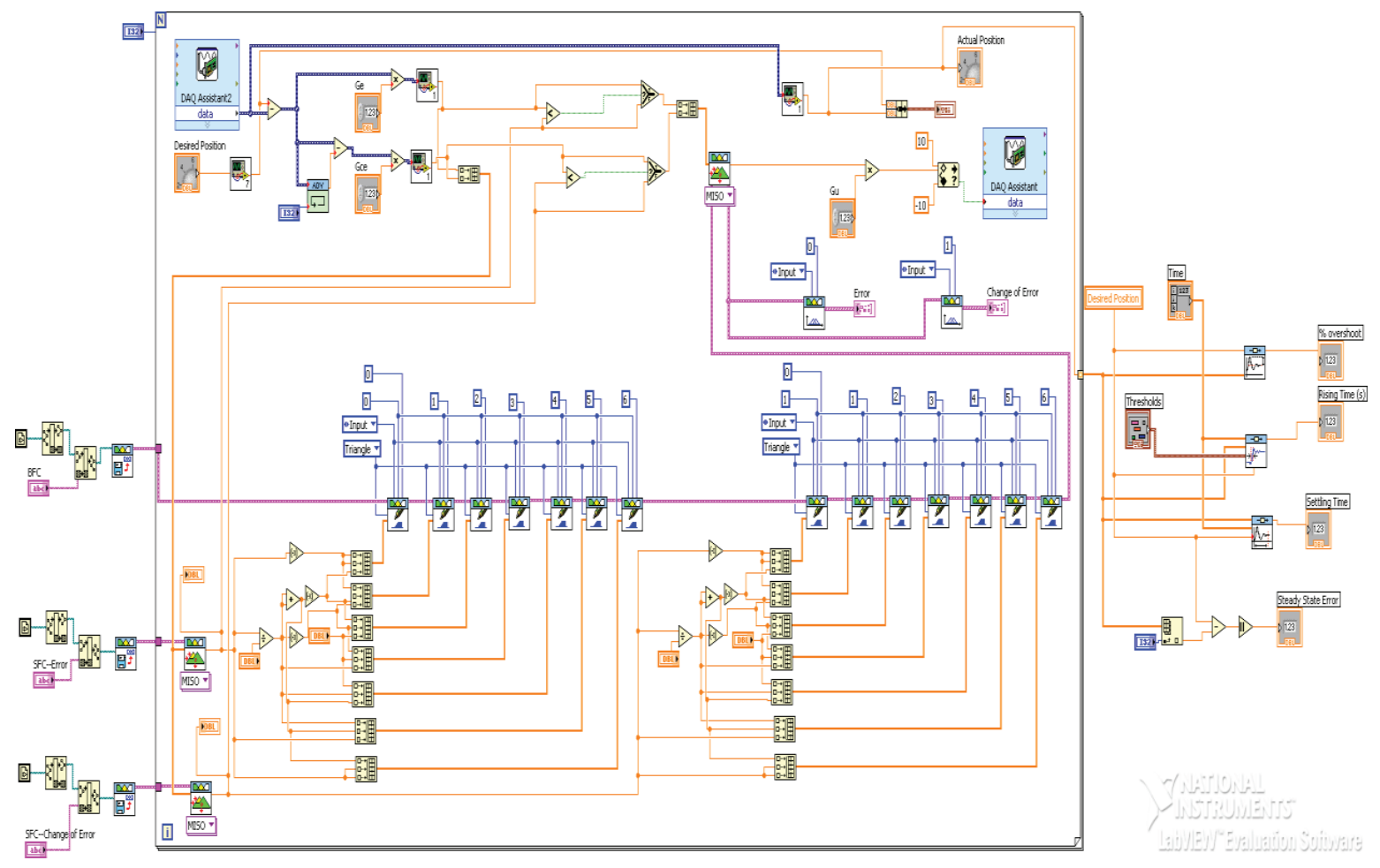

Figure 8. LabVIEW block diagram of the proposed system

To evaluate the proposed controller performance, several position tracks are applied using small rotation angles and large rotation angles with clockwise and anticlockwise directions as shown in figures 9,10,11, and 12 and the response parameters are summarized in tables IV,V, and VI.

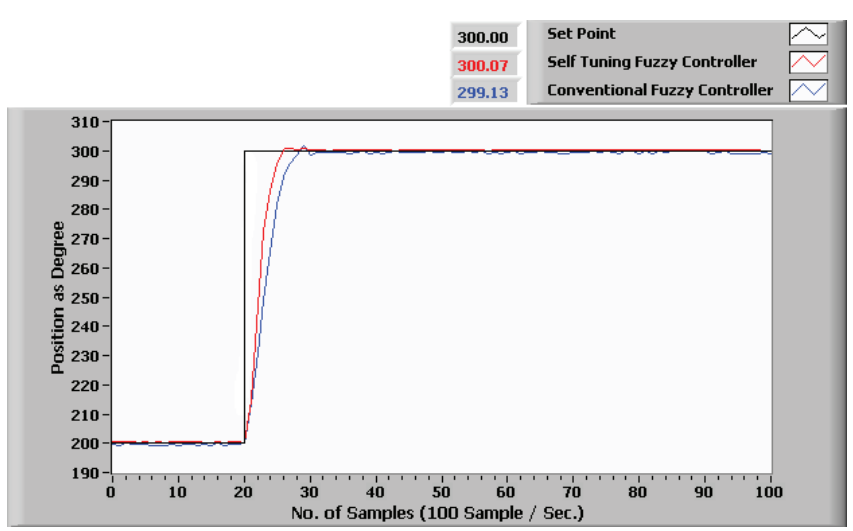

Figure 9. System response for a step from $200^{\circ}$ to $300^{\circ}$

TABLE IV. COMPARISON OF RESPONSE CHARACTERISTIC FOR FIGURE 9

\begin{tabular}{|c|c|c|c|c|}
\hline & $\begin{array}{c}\text { Peak } \\
\text { Overshoot } \\
\%\end{array}$ & $\begin{array}{c}\text { Settling } \\
\text { Time } \\
(\mathrm{Sec})\end{array}$ & $\begin{array}{c}\text { Rising } \\
\text { Time } \\
(\mathrm{Sec})\end{array}$ & $\begin{array}{c}\text { Steady } \\
\text { State } \\
\text { Error }\end{array}$ \\
\hline $\begin{array}{c}\text { Self Tuning } \\
\text { Fuzzy Controller }\end{array}$ & 0.61 & 0.07 & 0.06 & 0.07 \\
\hline $\begin{array}{c}\text { Conventional } \\
\text { Fuzzy controller }\end{array}$ & 2.5 & 0.08 & 0.07 & 0.87 \\
\hline
\end{tabular}

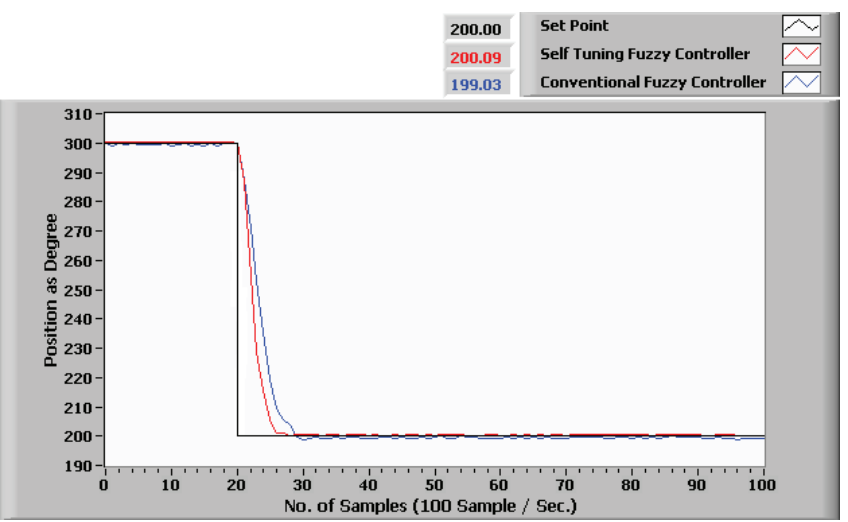

Figure 10. System response for a step from $300^{\circ}$ to $200^{\circ}$

TABLE V. COMPARISON OF RESPONSE CHARACTERISTIC FOR FIGURE 10

\begin{tabular}{|c|c|c|c|c|}
\hline & $\begin{array}{c}\text { Peak } \\
\text { Overshoot } \\
\%\end{array}$ & $\begin{array}{c}\text { Settling } \\
\text { Time } \\
(\mathrm{Sec})\end{array}$ & $\begin{array}{c}\text { Rising } \\
\text { Time } \\
(\mathrm{Sec})\end{array}$ & $\begin{array}{c}\text { Steady } \\
\text { State } \\
\text { Error }\end{array}$ \\
\hline $\begin{array}{c}\text { Self Tuning } \\
\text { Fuzzy Controller }\end{array}$ & 0.03 & 0.07 & 0.06 & $0.09^{\circ}$ \\
\hline $\begin{array}{c}\text { Conventional } \\
\text { Fuzzy controller }\end{array}$ & 0.48 & 0.09 & 0.07 & $0.97^{\circ}$ \\
\hline
\end{tabular}




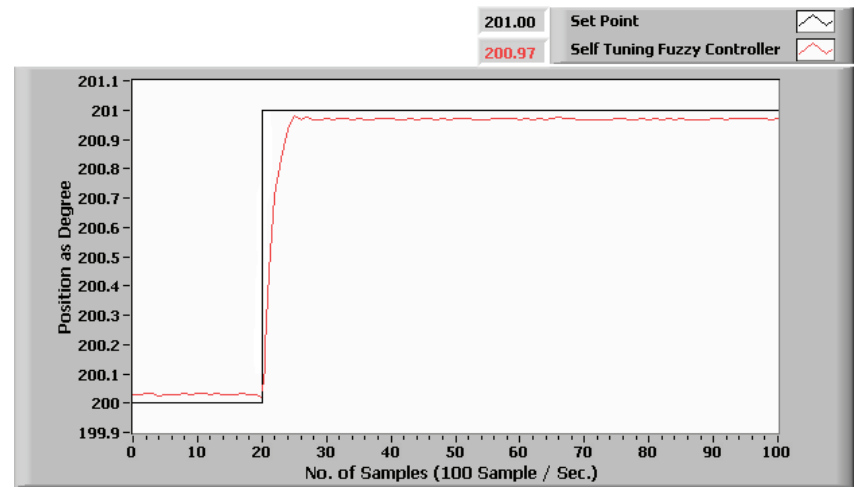

Figure 11. System response for a step from $200^{\circ}$ to $201^{\circ}$

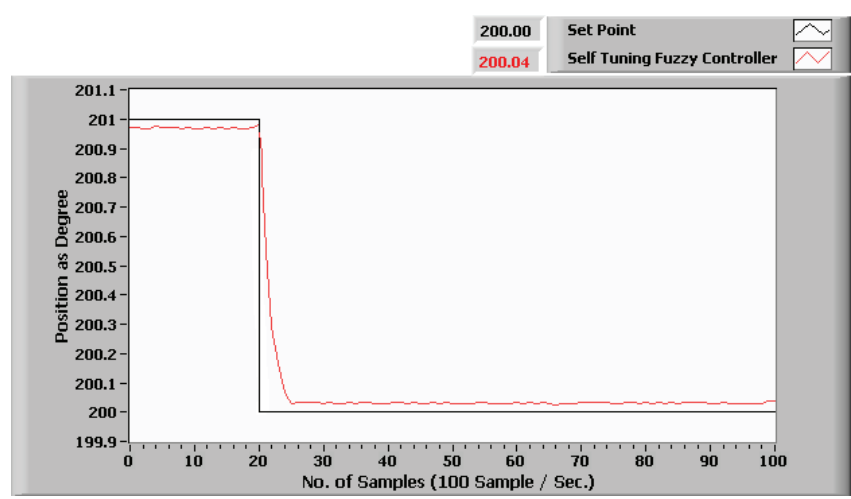

Figure 12. System response for a step from $201^{\circ}$ to $200^{\circ}$

TABLE VI. RESPONSE CHARACTERISTIC FOR FIGURE 11 AND 12

\begin{tabular}{|c|c|c|c|c|}
\hline $\begin{array}{c}\text { Self Tuning } \\
\text { Fuzzy } \\
\text { Controller }\end{array}$ & $\begin{array}{c}\text { Peak } \\
\text { Overshoot } \\
\%\end{array}$ & $\begin{array}{c}\text { Settling } \\
\text { Time } \\
\text { (Sec) }\end{array}$ & $\begin{array}{c}\text { Rising } \\
\text { Time } \\
(\text { Sec) }\end{array}$ & $\begin{array}{c}\text { Steady } \\
\text { State } \\
\text { Error }\end{array}$ \\
\hline $200--201$ & 1.55 & 0.04 & 0.03 & $0.03^{\circ}$ \\
\hline $201--200$ & 1.2 & 0.04 & 0.03 & $0.04^{\circ}$ \\
\hline
\end{tabular}

\section{CONCLUSION}

In this paper, a self tuning FLC is designed to control the position of D.C. motor when the rotation angle is small by varying the width of membership functions of BFC input variables using SFC. The resulting controller has the ability to maximize or minimize its accuracy by increasing or decreasing the resolution of its membership functions. To do this task, LabVIEW 2009 program is used which enables users to design and implement a dynamic fuzzy controller (modifying FLC parameters while running a plant). According to the real time results, the proposed adaptive FLC produces a better performance for small rotation angles and even if the rotation angle is large.

\section{REFERENCES}

[1] Christopher T. Kilian, "Modern Control Technology: Components and Systems", 2nd edition, Delmar Thomson Learning, ISBN-10: 076682358X, December 2000.

[2] Baldor Electric Company, "Servo Control Facts", a handbook explaining the basics of motion 2000.

[3] L.A. Zadeh, "Fuzzy Sets", information and control, vol. 8, pages: 338$353,1965$.

[4] I. Rojas, H. Pomares, J. Gonzalez, L.J. Herrera, A. Guillen, F. Rojas, O. Valenzuela, "Adaptive fuzzy controller: Application to the control of the temperature of a dynamic room in real time", Fuzzy Sets and Systems, Volume 157, Issue 16, Pages 2241-2258, 16 August 2006.

[5] Mokrani L. and Kouzi K., "Influence of Fuzzy Adapted Scaling Factors on the Performance of A Fuzzy Logic Controller Based on an Indirect Vector Control for Induction Motor Drive" , Journal of Electrical Engineering, VOL. 55, NO. 7-8, 188-194. ISSN 1335-3632, FEI STU 2004

[6] Y. P. Singh, "A modified self-organizing controller for real-time process control application", Fuzzy Sets Syst., vol. 96, no. 2, pp. $147-$ $159,1998$.

[7] H.X. Li and C.C. Lau, "Development of Fuzzy Algorithms for Servo Systems", IEEE Control Systems Magazine, , Volume: 9, Issue: 3 , pages: 65-72, April 1989.

[8] S. Mohan and S. Bhanot, "Comparative Study of Some Adaptive Fuzzy Algorithms for Manipulator Control", International Journal of Computational Intelligence, Volume 3 Number 4. pp. 303-311, 2007.

[9] J.A. Dunlop, K.J. Burnham, D.J.G. James, P.J. King, " A selfregulating scaling method for fuzzy control", Third IEEE Conference on Control Applications, Glasgow, page(s): 683 - 687 vol.1, Aug 1994.

[10] Seok-Yong Oh Dong-Jo Park, "On-line self tuning fuzzy controller using intelligent membership function", Proceedings of the 34th SICE Annual Conference, Hokkaido, page(s): 1317 - 1320, Jul 1995.

[11] Rajani K. Mudi and Nikhil R., "A Robust Self-tuning Scheme for PIand PD-Type Fuzzy Controllers", IEEE transactions on fuzzy systems, VOL. 7, page(s): 2-16, Feb. 1999. 